\title{
Morphological and Molecular Variability of Rhizoctonia solani Isolates Causing Banded Leaf and Sheath Blight in Maize
}

\author{
M. Madhavi ${ }^{1^{*}}$, P. Narayan Reddy ${ }^{2}$, R. Ranga Reddy ${ }^{3}$ and S. Sokka Reddy ${ }^{4}$ \\ ${ }^{1}$ Dept. of Plant Pathology, Agricultural College, Jagtial, Karimnagar, Telengana (505 529), India. \\ ${ }^{2}$ Dept. of Plant Pathology, ${ }^{4}$ Institute of Agricultural Biotechnology, College of Agriculture, Rajendranagar, \\ Hyderabad, Telengana (500 030), India \\ ${ }^{3}$ Maize Research Centre, Agricultural Research Station, Rajendranagar, Hyderabad, Telengana (500 030), India
}

\section{Article History}

Manuscript No. AR847

Received in $12^{\text {th }}$ July, 2014

Received in revised form $25^{\text {th }}$ April, 2015

Accepted in final form $24^{\text {th }}$ May, 2015

\section{Correspondence to}

${ }^{*} E$-mail: madhagonii@gmail.com

\section{Keywords}

Rhizoctonia solani, morphological variability, PCA, genetic variability

\begin{abstract}
Twenty seven isolates of Rhizoctonia solani causing Banded Leaf and Sheath Blight in maize were collected from different maize varieties and one from rice grown in various regions of Telengana State, India for easy breeding task. The isolates were analysed for their morphological and genetic characterization. The hyphal width varied from $5.00(\mathrm{RS} 2, \mathrm{RS} 20)$ to $7.97 \mu \mathrm{m}(\mathrm{RS} 10)$ of rice isolate $(7.34 \mu \mathrm{m})$. The isolates RS7, RS 8, RS9 (Karimnagar), RS10, RS11, RS12 (Khammam) RS16 (Krishna) and RS26 (Kurnool) and one rice isolate RS28 produced barrel shaped monilioid cells. The clamp connection was present only in RS1 isolate from Pragnyapur mandal of Medak district. The three isolates RS16, RS17, RS18 from Krishna district and rice isolate RS28 recorded maximum colony growth of $90.00 \mathrm{~mm}$ within $48 \mathrm{~h}$ of incubation. The colour of most isolates varied from light grey to brown while the rice isolate showed a typical yellowish brown shade. The sclerotial number per $5.00 \mathrm{~mm}$ culture disc of test isolates ranged from between (7.00) to (17.67). Their size varied between $0.21 \mu \mathrm{m}$ (RS 24) and $1.57 \mu \mathrm{m}$ (RS11). The rice isolate RS28 recorded highest (19.00) sclerotial count compared to that of maize isolates. Sclerotial colour in all isolates except for RS 24 was yellowish brown to dark reddish brown whereas the rice isolate was dark yellowish brown. Molecular characterization of the test isolates using RAPD markers with UPGMA exhibited two major clusters with 66 to $90 \%$ genetic similarity.
\end{abstract}

\section{Introduction}

Maize (Zea mays L.) is a $\mathrm{C}_{4}$, third most important cereal crop in the world agricultural economy. It is used as a source of food, feed and industrial products. Though, having a very high yield potential it is susceptible to several diseases. The banded leaf and sheath blight (BLSB) caused by Rhizoctonia solani f. sp. sasakii Exner, (Tel: Thanatephorus sasakii (Shirai) $\mathrm{Tu}$ and Kimbro) is a very destructive disease of maize and considered to be the major constraint for limited production. This pathogen causes losses in grain yield ranging from 11.0 to $40.0 \%$ (Singh and Sharma, 1976). The disease was reported for the first time from Srilanka (Bertus, 1927) under the name 'Sclerotial" disease. Subsequently, the disease was reported in Malaysia and Philippines (Reyes, 1941). In recent years, disease outbreak epidemics were reported in several countries. In India, the disease was first reported in 1966 by Payak and Renfro. Besides India, it has been found to exist in several hot and humid tropical maize growing areas of Srilanka, Bhutan,
Indonesia, Japan, Korea, Malaysia, Myanmar, Nepal, Pakistan, Philippines, Southern China, Thailand and Vietnam.

Increased incidence of BLSB has been observed in rice fallow maize crop (zero tillage) in different districts of Telengana State due to increased application of nitrogenous fertilizers and cultivation of single cross hybrids during rabi season. The disease causes loss in yield due to premature death, stalk breakage, cob infection (ear rot) in susceptible cultivars of maize affecting the quality of the produce. Rhizoctonia $\mathrm{sp}$ belong to a group of ubiquitous and diverse plant pathogens, causing economically important diseases in a wide range of tropical, sub tropical and temperate conditions. The variability in the pathogen considerably complicates the host range and resistance screening for host material to counter the pathogen. Without a clear knowledge of strains present in a particular cropping ecosystem it is very difficult to conclude the etiology as well as to select varieties for areas under this ecosystem. Hence, upto date knowledge of existence of physiological races 
or pathotypes of pathogen in the state is needed. This could be achieved based on the distinct variations in the pathogens in relation to their pathogenicity. Since $R$. solani is a variable pathogen and had a wide host range and so far, no attempt has been made to define variability of $R$. solani in relation to spatial distribution in Telengana State, the genetic differences underlying $R$. solani populations collected from different maize growing districts of Telengana State will provide a useful information of the pathogen.

Variability studies among maize isolates of $R$. solani from Telengana State based on DNA polymorphism has so far not been done. Thus, the need was felt to substantiate biological pathotyping with DNA polymorphism based variability studies. Keeping this in view, the present study was undertaken to analyze the variability within $R$. solani isolated from different regions with respect to morphological and molecular characteristics.

\section{Materials and Methods}

The studies were conducted in the Department of Plant Pathology, in collaboration with the Department of Biotechnology, College of Agriculture, Acharya N.G. Ranga Agricultural University, Rajendranagar, Hyderabad, Telengana (500 030), India

\subsection{Source of $R$. solani isolates}

Twenty seven isolates of Rhizoctonia solani infecting maize were obtained from various maize varieties (and one from rice) grown in different regions of Telengana State. The fungal isolates were purified by single hyphal tip method and each isolate was maintained as pure culture on potato dextrose agar (PDA) at $4{ }^{\circ} \mathrm{C}$. The isolates of the pathogen were identified based on the morphological, cultural and sclerotial characteristics with the help of relevant monograph and illustrated books. The cultures were also sent for identification to Indian Type Culture Collection IARI, New Delhi, India. These isolates were sub-cultured on PDA slants and kept in a refrigerator for further studies.

\subsubsection{Morphological characterization of isolates}

Isolates of $R$. solani obtained from maize and rice were subcultured on PDA medium in petri plates $(90 \mathrm{~mm}$ diameter) for comparision of morphological and growth characters. A $5 \mathrm{~mm}$ disc from margins of an actively growing seven day-old fungal colony of each isolate was inoculated in the center of petri plate containing PDA. Three plates were used for each isolate. Colony growth rate was recorded by measuring colony diameter after $24,48,72,96$, and $120 \mathrm{~h}$ at $25 \pm 2{ }^{\circ} \mathrm{C}$. Colony colour and texture ((Munsell colour Company, Inc. 1954) were recorded 10 days after incubation. Based on the colony pigmentation, the cultures were assigned to different groups based on dominant spectral colour. The hyphal width was measured by using ocular micrometer under microscope after four days of incubation and mycelial dry weight was recorded ten days after incubation (Basu et al., 2004).

Sclerotial characters of each isolate were observed after 15 days of incubation. The sclerotial number was calculated by counting number of sclerotia $5 \mathrm{~mm}^{-1}$ culture disc under binocular microscope. Five colony discs were used to count sclerotial number. Sclerotial size was measured using digital vernier calipers. Sclerotial arrangement and colour (Munsell Soil Colour Chart) were also recorded. Also the morphological, cultural and sclerotial characters was assessed through. Principle Component Analysis.

\subsubsection{Molecular characterization of isolates}

The molecular variability among twenty eight isolates of R. solani was studied using Random Amplified Polymorphic DNA (RAPD). Standard protocols were used for the isolation of DNA and RAPD analysis (Williams et al., 1990).

DNA fingerprint data generated by RAPD markers were converted into binary matrix. The presence (1) and absence (0) of each DNA band of a specific molecular weight was recorded for each gel. The binary matrix obtained from individual gel and data were analysed by using DICE coefficient and UPGMA method with NTSYS computer software (Rohl, 1993) and dendrogram was constructed.

\section{Results and Discussion}

\subsection{Morphological variability among $R$. solani isolates}

Among the 28 isolates studied for their morphological characters, light microscopy studies revealed that all the isolates including rice isolate of $R$. solani characteristically branched out at right angle towards the distal end of the cell except in isolates RS7, RS20 and RS26 from Jagityal, Mangalgiri and Atmakur mandals which showed right angled branching in the middle of the cell. Except for the isolate RS 19 from Tenali, all other isolates including rice isolate showed a characteristic constriction at the point of branching.

Out of 27 maize isolates, eight isolates i.e. RS7, RS8, RS9 (Karimnagar), RS10, RS11, RS12 (Khammam) RS16 (Krishna) and RS26 (Kurnool) and one rice isolate RS28 produced barrel shaped monilioid cells in addition to ordinary vegetative hyphae. The isolates RS7 from Jagityal mandal of Karimnagar district and RS26 from Atmakur mandal of Kurnool district though belonged to Telangana and Rayalaseema regions showed distinct variation with respect to right angled branching, presence of constriction at the point of branching and monilioid cells. Clamp connection was observed only in RS1 isolate from Pragnyapur mandal of Medak district. The hyphal width of all the 28 isolates including one rice isolate $(7.34 \mu \mathrm{m})$ varied from 5.00 (RS2, RS20) to $7.97 \mu \mathrm{m}$ (RS10). 
However the hyphal width of rice isolate RS28 was on par with RS10, RS11 (Khammam) and RS16 (Krishna) isolates of maize respectively (Table 1).

Investigations on the morphological features under light microscopy revealed that all the isolates possessed the basic characteristics of $R$. solani. An obvious observation for the mycelium branching out at right angles, presence of characteristic constriction at the point of branching (except for isolate RS19) and formation of septum near the point of origin of the branch, hyphal width $>5.00 \mu \mathrm{m}$, presence of monilioid cells, absence of clamp connections (except for RS1) were visualized under light microscopy. These were the characters of immense taxonomical importance as described by the previous workers Duggar, 1915; Matsumato, 1921; Thomas, 1925; Ritcher and Schneider, 1953; Parmeter and Whitney, 1970; Bracker and Butler, 1963; Saksena and Vaartaja (1961) for the identification of Rhizoctonia solani (Kuhn). The present findings on morphological variability among $R$ solani isolates are in accordance with Srinivas (2002) in maize, Singh et al. (1999); Vineeta Singh et al. (2002); Basu et al. (2004) in rice. Morphological variability among isolates of $R$. solani from rice, maize and other hosts were reported by Meena et al. (2001); Singh et al. (2002).

The colony colour in most of the isolates varied from light gray to brown. Based on pigmentation/dominant spectral colour from Munsell's soil colour chart (1954), the cultures were assigned to four colour groups with respective shade numbers under them. i.e. Group I- 2.5 Y, Group II-10Y, Group III-7.5 YR and Group IV 10 YR. Among the maize isolates, RS13 (7/1-10Y) from Janagoan mandal of Warangal district and RS24 (8/1-2.5 YR) from Jeelugumilli mandal of West Godavari district showed light greenish gray Gley 1 and white colony colour, respectively. While the rice isolate (RS28) showed a typical yellowish brown shade (5/6-10 YR). The discoloration of the growth media is mainly attributed to the production of pigments by the pathogen. The differences in the intensity of the colour may also correspond to the amount of pigments released by respective isolate in the media. The colour production may also be due to release of other secondary metabolites like toxins. Zhang et al. (1995) allocated turf grass isolates of $R$. solani to different AG groups based on colony pigmentation. Similarly, Srinivas (2002) categorised maize isolates of $R$. solani causing BLSB disease based on colony pigmentation.

Based on the texture of mycelial growth and colony appearance the isolates were categorised into three groups i.e. group-I fluffy, group II slightly fluffy and group III flat. The observations indicated that most of the isolates had colony growth that was flat either with straight and sparse mycelia growth or staright and compact type of colony.
The mycelial dry weight of rice isolate RS28 $(47.80 \mathrm{mg})$ did not differ significantly with $R$. solani isolates of maize except with the isolates RS1, RS2, RS3, RS6 and R23 with 60.43, $69.93,64.33,62.40$ and $56.53 \mathrm{mg}$, respectively. Isolates RS2, RS3, RS6, RS12 and RS24 had fluffy texture, abundant mycelium and high mycelial dry weights. The mycelial dry weight recorded by the $R$. solani isolates showed high degree of variation which ranged from $42.60 \mathrm{mg}$ to $69.93 \mathrm{mg}$ and the findings are in accordance with Basu et al. (2004) who recorded the mycelial dry weight of multinucleate $R$. solan $i$ isolates belonging to AG1 A group ranging from 42.8 to 69.7 mg (Table 1).

The variability in the growth rate of $R$. solani isolates was observed during period of $24 \mathrm{~h}$ to $120 \mathrm{~h}$ of incubation. After 48 $\mathrm{h}$ of incubation, isolates of maize from Krishna district RS16, RS17, RS18 and rice isolate RS28 have attained $90.00 \mathrm{~mm}$ growth with growth rate of 46.33, 42.33, 41.67 and $46.67 \mathrm{~mm}$ per day. After $72 \mathrm{~h}$ incubation, the growth recorded in isolates RS1 to RS12, RS25 to RS27 was $90.00 \mathrm{~mm}$. The isolate RS21 had maximum growth rate of $30.67 \mathrm{~mm}$ day $^{-1}$, while the least growth rate $7.00 \mathrm{~mm}$ day ${ }^{-1}$ was observed in isolate RS24. After $96 \mathrm{~h}$ of incubation, the isolates RS13, RS15, RS19 and RS20, RS22 and RS23 from Jeelugumilli, Hasanparthy, Tenali, and Mangalgiri mandals, respectively have attained $90.00 \mathrm{~mm}$ diameter, wherein the isolates RS20 had maximum $45.67 \mathrm{~mm}$ day $^{-1}$, RS19 $(42.33 \mathrm{~mm})$ growth rate and least $8.33 \mathrm{~mm}_{\text {day }}{ }^{-1}$ in isolates RS22 and RS23. Though the isolates RS14, RS21 RS24 recorded a colony growth of $70.33 \mathrm{~mm}, 73.00 \mathrm{~mm}$ and $69.67 \mathrm{~mm}$ respectively, after $120 \mathrm{~h}$ of incubation these isolates have recorded $90.00 \mathrm{~mm}$ colony growth (Table 2).

Significant variations with respect to colony growth and growth rate was also observed among the isolates. The isolates RS11, RS16, RS17, RS18 and rice isolate RS28 having maximum growth rate were found more virulent as they induced susceptible reaction on maize, while the isolates RS14, RS21 and RS24 showing least growth rate were less virulent. Meena et al. (2003) observed that the fast growing isolate of $R$. solani from maize was found to be more virulent on a susceptible maize cultivar. Also in their study, Thind and Aggarwal (2008), Khodaryari et al. (2009); Guleria et al. (2007) stated that the $R$. solani isolates from rice were fast growing with $>20 \mathrm{~mm}$ mycelial growth rate day ${ }^{-1}$ indicating their fast growing nature.

The cultural characteristics studied among the R. solani isolates with respect to the colony colour, colony texture, mycelial dry weight, colony diameter and growth rate revealed the existence of significant variation among the isolates. Singh et al. (1999) assigned Munsell's soil colour chart shade number to the colony colour of $R$. solani isolates from rice, maize, soybean, mung beans and cotton. In the present study two 


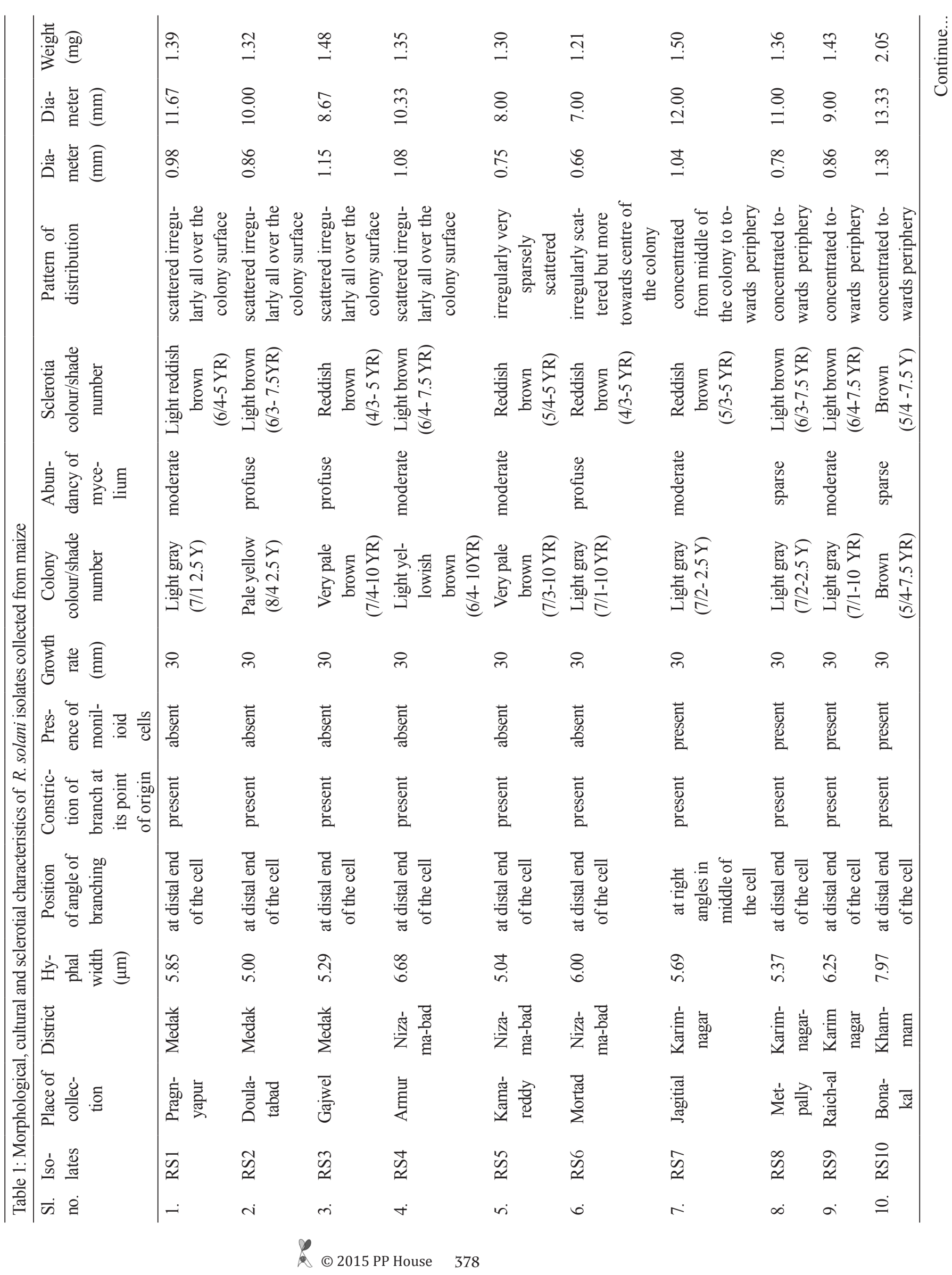




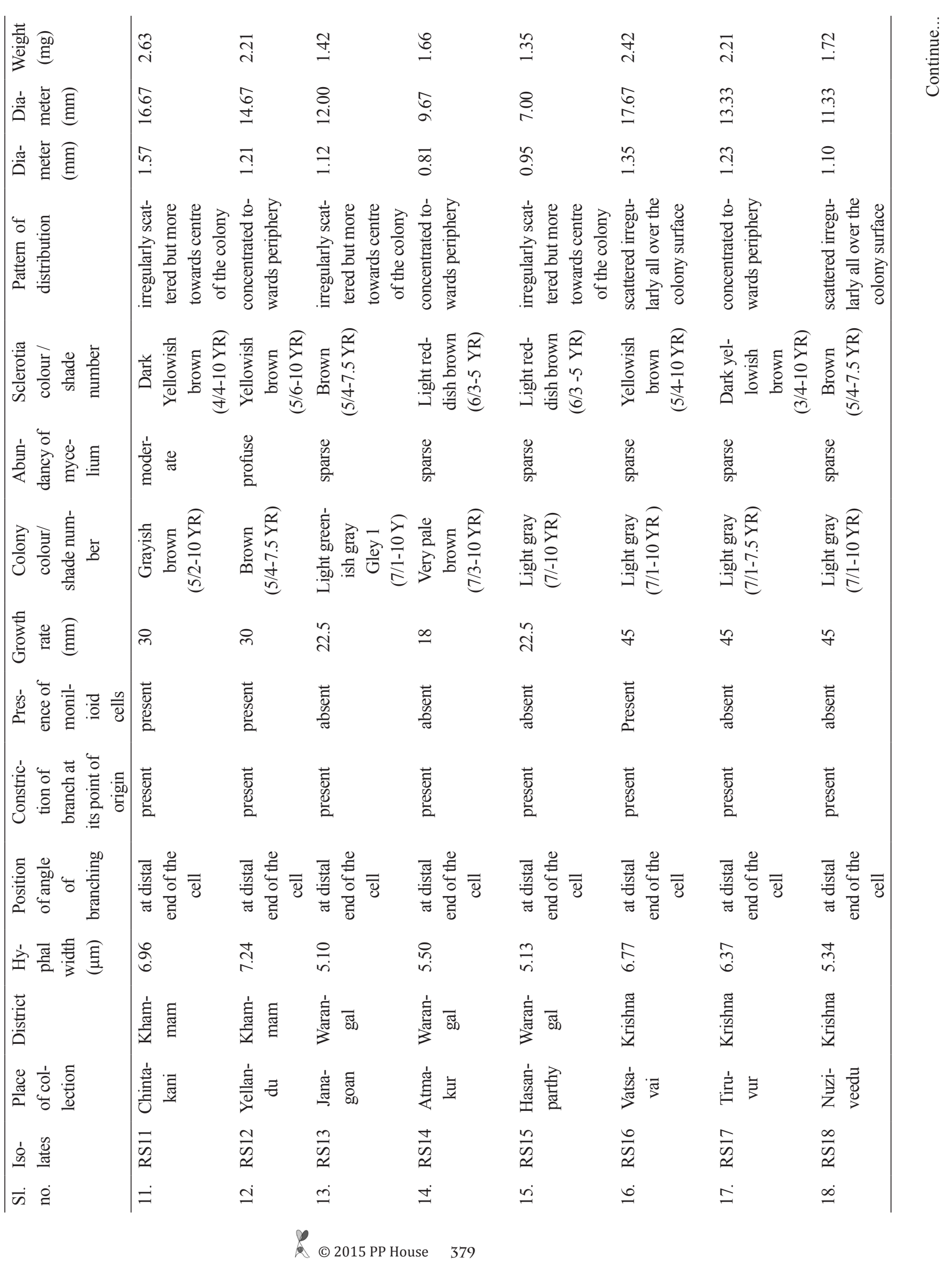




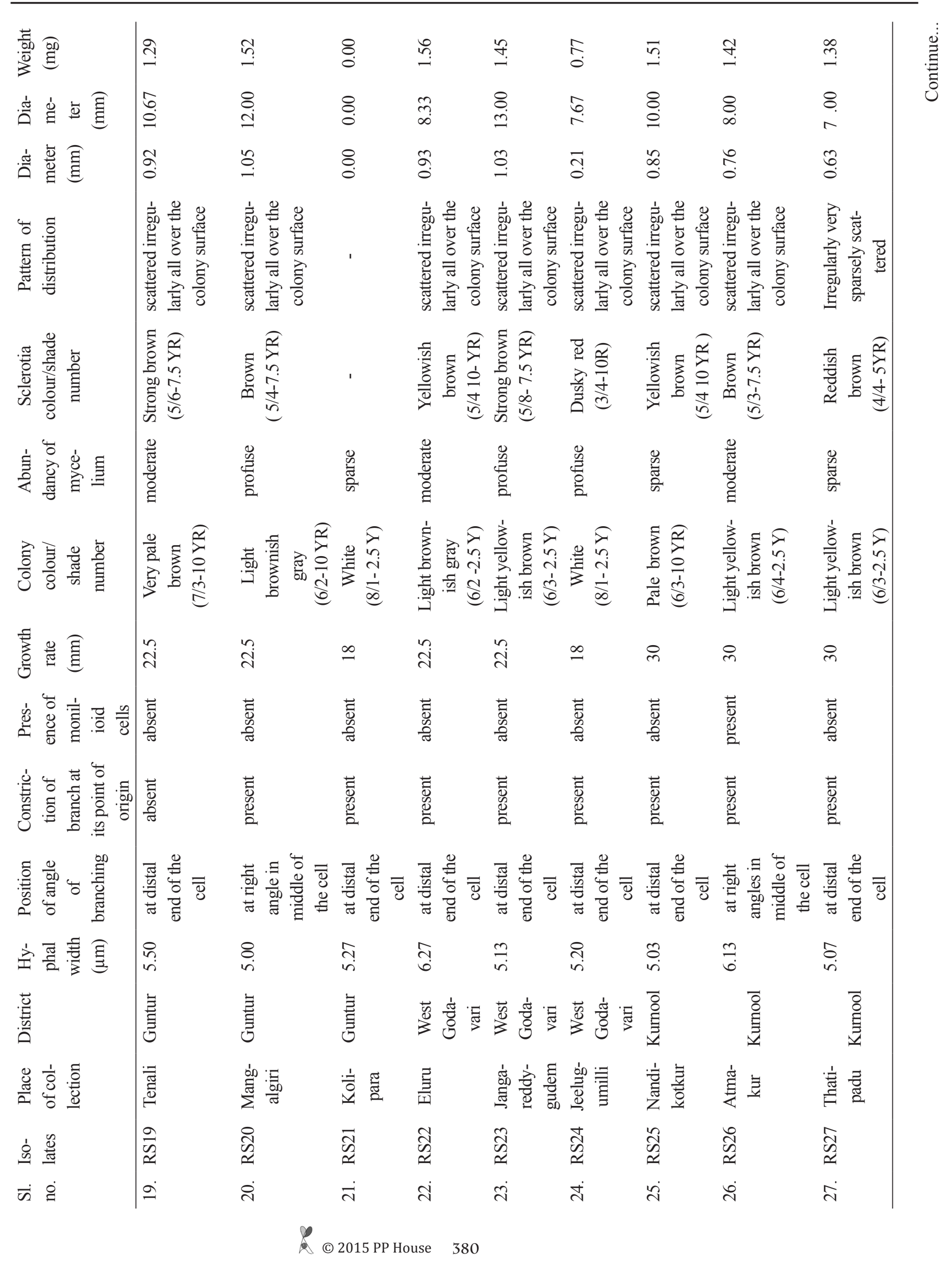




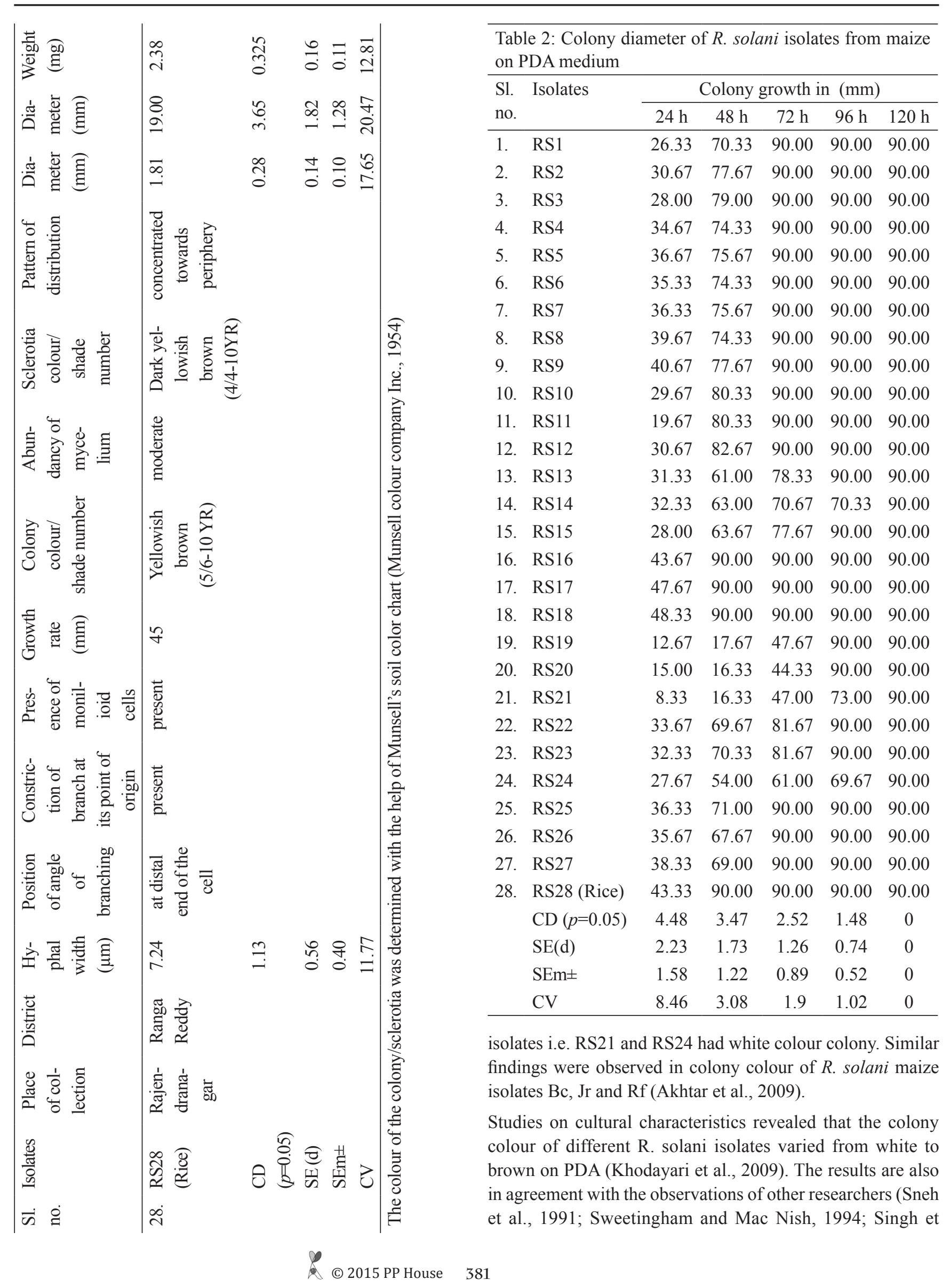


al., 1999). Distinct differences were observed in the colony appearance and the isolates were categorised into different groups based on texture and abundance of mycelium. The distinct colony growth of abundant cottony mycelia growth was seen in RS2, RS3, RS6, RS12 and RS24 isolates. It may be due to the inherent nature of these isolates to go for quick and profuse mycelial growth in early stages of growth before setting the sclerotia. Similar observations have been made by Toda et al. (1999) who divided Rhizoctonia AG-D isolates into two subgroups AG-D (I) and AG-D (II), based on the results of cultural characteristics Srinivas (2002) categorised the $R$. solani f.sp. sasakii isolates from maize based on texture and abundance of their mycelial growth and colony appearance. Guleria et al. (2007) used cultural characters for differentiating the $R$. solani isolates from rice.

Sclerotial characteristics also varied among isolates. Sclerotial colour in all isolates except for RS 24 was yellowish brown to dark reddish brown whereas the rice isolate was dark yellowish brown. The colour of the sclerotia was categorised into three groups based on pigmentation or dominant spectral colour i.e. category I-5 YR, category II- 7.5 YR and category III- 10 YR from Munsell's soil colour chart. Most of the isolates had spectral colour of 7.5 YR.

Based on pattern of sclerotia formation the isolates were divided into 4 categories (Table 1). Sclerotia of most of the isolates were formed in irregular manner scattered all over the colony surface, whereas sclerotia of rice isolate RS28 were concentrated near the edge of the colony. More number of sclerotial aggregation was observed in isolates RS11, RS12 followed by RS13, RS15 and RS16. A significantly higher sclerotial weight was noted in RS11 $(2.63 \mathrm{mg})$ followed by RS16 (2.42 mg). Isolate RS24 had least weight of $0.77 \mathrm{mg}$, whereas the isolates RS12 (Yellandu) and RS17 (Tiruvur) have shared equal sclerotial weight of $(2.21 \mathrm{mg})$. Sclerotial weight of rice isolate RS28 $(2.38 \mathrm{mg})$ was statistically on par with that of maize isolate RS11 (Chintakani) and RS16 (Vatsavai). Such type of sclerotial categorisation was followed by Thind and Aggarwal (2008) for potato and rice isolates. Further, it is it is evident that most of the isolates had a sclerotial size range of $0.21 \mu \mathrm{m}$ (RS24) to $1.57 \mu \mathrm{m}$ (RS11). The rice isolate RS28 produced significantly higher $(1.81 \mu \mathrm{m})$ sclerotial diameter. On the basis of sclerotial diameter, the isolates were grouped into different categories i.e. group-I $(<0.5 \mu \mathrm{m})$, group-II $(0.5-1.0 \mu \mathrm{m})$, group-III $(1.0-1.5 \mu \mathrm{m})$ and group-IV $(>1.5 \mu \mathrm{m})$ (Table 1) .

The sclerotial number per $5.00 \mathrm{~mm}$ colony disc was maximum (17.67) in isolate RS16 followed by RS11 (16.67) and RS12 (14.67) and it was minimum (7.00) in isolates RS6, RS27. The rice isolate RS28 recorded highest (19.00) sclerotial count compared to that of maize isolates.
The sclerotia produced by different isolates was at first white turning brown with maturity. Colour of the sclerotia was observed using Munsell's soil colour chart (1954). Based on the dominant spectral colour/pigmentation of the sclerotia, the isolates were assigned to three groups. The only character that clearly distinguished the sclerotia was the colour as reported by Anderson (1982). Srinivas (2002) assigned the sclerotia of $R$. solani isolates causing BLSB in maize into three different colour groups based on pigmentation. Similar categorisation of the sclerotia produced by the $R$. solani isolates in the rice was assigned as per Munsell's soil colour chart by Singh et al. (1999), Thind and Aggarwal (2008) in potato and rice isolates.

The arrangement and pattern of formation of sclerotia produced by $R$. solani isolates in the culture varied greatly and were divided into four categories. However most of the isolates had sclerotia which conglomerated at the centre of the colony. Such type of categorisation based on the pattern of formation and arrangement among maize isolates of $R$. solani was done by Srinivas (2002), rice isolates Singh et al. (1999) and sclerotia from potato and rice isolates by Thind and Aggarwal (2008).

In the present investigation isolate RS21 did not produce sclerotia. Sclerotia may be absent in some $R$. solani isolates under certain cultural conditions therefore the absence of sclerotia does not exclude a mycelium from $R$. solani (Meyer, 1965); (Parmeter and Whitney, 1970).

Higher sclerotial aggregation was observed in isolates RS11 and RS12. The behaviour of the pathogen to grow quickly and produce sclerotia may increase the chances of pathogen to survive in the next season. High sclerotial aggregation, though hinder in quick dispersal, helps in increasing the chances of germination because of the enhanced surface area. In most of the isolates, sclerotia were produced on the surface of the colony, while isolate RS2 had aerial sclerotia. However, the sclerotia were aerial and submerged in the medium in RS24 isolate. Akhtar et al. (2009) revealed that the sclerotia of maize $R$. solani isolates $\mathrm{lt}$ and $\mathrm{Rf}$ were located on the surface of the colony; isolate $\mathrm{Hc}$ produced on subsurface while in isolates $\mathrm{Be}$ and $\mathrm{Jr}$, sclerotia were embedded in the medium.

In the present study though there is a correlation between the bigger size of sclerotia and highest virulence in case of RS11 isolate similar pattern was not followed in other isolates. However, size of sclerotia and virulence of the pathogen have been correlated by earlier researchers (Basu and Gupta, 1992). Basu et al. (2004) stated that there was no correlation between the mycelial growth of an $R$. solani rice isolate and its virulence on the host. It was the abundance and size of the sclerotia that determined the virulence of an isolate.

Principal component (PCA) 2D analysis using Jaccard's 
similarity with regard to morphological, cultural and sclerotial characters grouped 28 isolates into nine similarity groups. Considerable differences between the clusterswere detected in all the three characters studied among the isolates. The R. solani isolates were randomly distributed in different cluster groups disregarding their origin from where they were collected. The results indicated that the diversity among the isolates was not correlated with their origin of collection. The results of the present study are in agreement with that of Goswami et al. (2010); Bard et al. (1996) who reported morphological variations among the $R$. solani isolates collected from potato, mung bean, cauliflower, cabbage, amaranthus and grasses using cluster analysis and stated that these differences do indicate the existence of variability among the isolates of $R$. solani.

\subsubsection{Molecular Variability of R. solani isolates}

The RAPD DNA fingerprints generated from different isolates were compared visually to generate haplotype groupings for the 21 primers, isolates showing $100 \%$ similarity in banding pattern were classified in one haplotype group (Figure 1). The genetic relatedness was greater among the isolates RS2RS3 (Medak); RS22-RS24 (West Godavari) and RS19-RS20 (Guntur). This supports the assertion of Pascual et al. (2000); Jabaji-Hare et al. (1990), who emphasized that within an Ag in $R$. solani, genetic relatedness was greater among isolates from a common geographic origin that among isolates from distant geographic areas.

Cent percent genetic similarity was observed amongst RS17RS9 isolates originating from regions of Andhra and Telangana. This may indicate that migration has occurred, and that it plays a role in population structure and diversity. Migration might have occurred via human activity, such as the movement infested soil, or through natural mechanisms such as wind dispersal of infested organic material. However considerable similarity for the above said isolates suggest that these $R$. solani isolates might have spread from a common source at some time, with local adaption taking place, while the rest of the isolates from different locations were clearly distinct. This

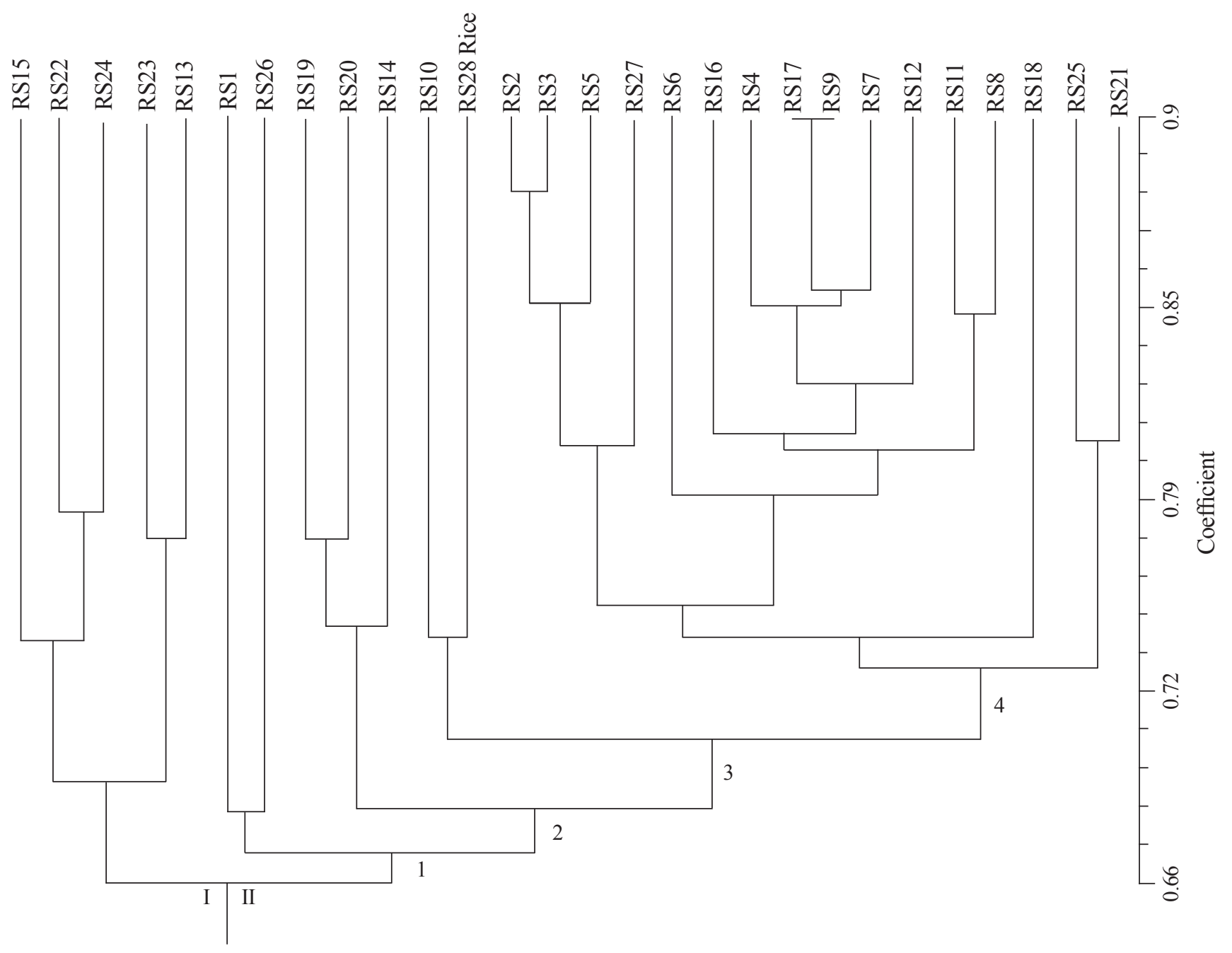

Figure 1: Grouping of R. solani isolates based on genetic similarities using RAPD markers 
may indicate the different paths of evolutionary development of AG-1 IA R. solani isolates infecting maize within Telengana State, suggesting that perhaps AG1IA is polyphyletic. The findings are in agreement with Stodart et al. (2007) among $R$. solani AG-2 isolates.

Polymorphisms evident from the dendrogram based on RAPD banding patterns of the isolates are also in line with the variation observed in the virulence test. The highly virulent isolates from the study including the most virulent one, were grouped in different sub-clusters of cluster II. Whether this variation was triggered by the teleomorph or by the heterokaryotic nature of $R$. solani (Bolkan and Butler, 1973; Puhalla and Carter, 1976, Julian et al., 1996; Pascual et al., 2000) remains to be determined. Khodayari et al. (2009) the results of molecular analysis did not show any correlation between $R$. solani isolates of rice and their geographical origins. Also no correlation between pathogenicity and genetic diversity was observed.

The RAPD method revealed polymorphism within isolates of $R$. solani and $R$. bataticola thereby indicating usefulness of DNA fingerprinting for race/biotype characterization. However, no strict correlation was observed between isolates grouped based on pathogenicity, morphological features and RAPD fingerprinting (Monga et al., 2007).

\section{Conclusion}

$R$. solani isolates collected from maize growing regions of Telengana State are quite variable with respect to genetic behavior and did not exhibit any similarities with morphological characters. Thus the studies states the existence of variation among the isolates.

\section{Acknowledgement}

Main author is thankful to Head, Department of Plant Pathology, College of Agriculture, Rajendranagar, Hyderabad, Telengana State for providing basic facility to study the morphology characters of $R$. solani isolates. And also to the Head, Institute of Agricultural Biotechnology, College of Agriculture, Rajendranagar for providing facilities to carry out molecular work.

\section{References}

Akhtar, J., Jha, V.K., Kumar, A., Lal, H.C., 2009. Occurrence of banded leaf and sheath blight of maize in Jharkhand with reference to diversity in Rhizoctonia solani. Asian Journal of Agricultural Sciences 1(2), 32-35.

Anderson, N.A., 1982. The genetics and pathology of Rhizoctonia solani. Annual Review of Phytopathology 20, 329-347.
Bard, R.E., Caning, D.E., Mullinix, B.G., 1996. Characterization and comparison of isolates of Rhizoctonia solani AG-7 from Arakansas. Plant Disease 80(12), 1421-1424.

Basu, A., Gupta, P.K.S., 1992. Cultural and pathogenic variation in rice isolates of Rhizoctonia solani Kuhn. Beitrage zur Tropischen Landwirtschaft and Veterinarmedizin 30(3), 291-297.

Basu, A., Podder, M., Prasanta, K., Sengupta., 2004. Variability and anastomosis among the rice isolates of Rhizoctonia solani. Indian Phytopathology 57(1), 70-72.

Bertus, L.S., 1927. A sclerotial disease of maize due to Rhizoctonia solani (Kuhn). Year Book, Dept. Agri. Cylone, 46-48.

Bolkan, H.A., Butler, E.E., 1973. Studies on heterokaryosis and virulence of Rhizoctonia solani. Phytopathology 64, 515-522.

Bracker, C.K., Butler, E.E., 1963. The ultrastructure and development to septa in hyphae of Rhizoctonia solani. Mycologia 55, 35-58.

Duggar, B.M., 1915. Rhizoctonia crocorrum (Pers.) DC., $R$. Solani kuhn (Corticium vagum $\mathrm{B}$ and $\mathrm{C}$ ) with notes on other species. Ann. Missouri Botan. Garden. 2, 403458.

Goswami, B.K., Bhuiyan, K.A., Mian , I.H., 2010. Morphological and pathogenic variations in the isolates of Rhizoctonia solani in Bangladesh. Bangladesh Journal of Agricultural Research 35(3), 375-380.

Guleria, S., Aggarwal, R., Thind, T.S., Sharma, T.R., 2007. Morphological and pathological variability in rice isolates of Rhizoctonia solani and molecular analysis of their genetic variability. Journal of Phytopathology $155,654-661$.

Parmeter, J.R., Jr., and whitney H.S., 1970. Taxonomy and momenclature of the imperfect state. In: Parmeter, J.R. (Ed.), Biology and Pathology of Rhizoctonia solani. , 255. University of California Press, Berkeley, 7-9.

Jabaji-Hare, S.H., Meller, Y., Gill, S., Charest, P.M., 1990. Investigation of genetic relatedness among anastomosis groups of Rhizoctonia solani using cloned DNA probes. Canadian Journal of Plant Pathology 12, 393-404.

Julian, M.C., Debets, F.,Keijer J.,1996. Independence of sexual and vegetative incompatibility mechanisms of Thanatephorus cucumeris (Rhizoctonia solani) anastomosis group 1. Phytopathology 86, 566-74.

Khodayari, M., Safaie, N., Shamsbakhsh, M., 2009. Genetic diversity of Iranian AG1-IA isolates of Rhizoctonia solani, the cause of rice sheath blight, using morphological and molecular markers. Journal of Phytopathology 157(11/12), 708-714.

Matsumoto, T., 1921. Studies on the physiology of the fungi 
XII. Physiological specializeation in Rhizoctonia solani kuhn. Annual Missouri Botany Garden 8, 1-62.

Meena, B., Ramamoorthy, V., Muthusamy, M., 2001. Morphological and pathological variations in isolates of Rhizoctonia solani causing sheath blight of rice. Plant Disease Research 16(2), 166-172.

Meena, R.L., Rathore, R.S., Kusum Mathur, 2003. Evluation of fungicides and plant extracts against banded leaf and sheath blight of miaze. Indian Journal of Plant Protection 31(1), 94-97.

Meyer, R.W., 1965. Heterokaryosis and Nuclear Phenomenon in Rhizoctonia. Ph.D.Thesis, University of California, Berkeley, 118.

Monga, D., Kumar, M., Kumar, R., Saini, N., Chakrabarty, P.K., 2007. Characterization of cotton root rot pathogens - Rhizoctonia solani and R. bataticola using RAPD and morphological markers. Indian Phytopathology 60(2), 259-263.

Pascual, C.B., Hyakumachi, M., 2000. Distribution of vegetatively compatible populations of Rhizoctonia solani AG-1 $1 \mathrm{~A}$ in a field planted with different host species. Journal of General Plant Pathol 66, 206-209.

Payak, M.M., Renfro. B.L., 1966. Diseases of maize new to India. Indian Phytopathological Society Bulletin 3, 14-18.

Puhalla, J.E., Carter, W.W., 1976. The role of the H locus in hetero-karyosis in Rhizoctonia solani. Phytopathology $66,1348-1353$.

Reyes, G.M., 1941. Notes on diseases affecting maize in Philippines. Philippine Journal of Agriculture 12, 6169.

Richter, R., Schneider, R., 1953. Unterruchungen Zear Morphologische and Biologischen Differen-ziercing Von Rhizoctonia solani, Phytopath Z. 20, 167-226.

Rohlf, F.J., 1993. NTSYS Pc. Numerical taxonomy and multivariate analysis system. Exter Publishing, Setauket, New York.

Saksena, H.K., Vaartaja, O., 1961. Taxonomy, morphology and pathogenicity of Rhizoctonia species from forest nurseries. Canadian Journal of Botany 39, 627- 647.

Singh, B.M., Sharma, Y.R., 1976. Evaluation of maize germplasm to banded sclerotial disease and assessment of yield loss. Indian Phytopathology 29, 129-132.

Singh, A., Singh, U.S., Willocquet, L., Savary, S., 1999. Relationship among cultural/morphological characteristics, anastomosis behaviour and pathogenicity of Rhizoctonia solani Kuhn on rice. Journal of Mycology and Plant Pathology 29(3), 306-316.
Singh, V., Singh, U.S., Singh, K.P., Singh, M., Kumar, A., 2002. Genetic diversity of Rhizoctonia solani isolates from rice: differentiation by morphological characteristics, pathogenicity, anastomosis behaviour and RAPD fingerprinting. Journal of Mycology and Plant Pathology $32,332-344$.

Sneh, B., Burpee, L., Ogoshi, A., 1991. Identification of Rhizoctonia species. American Phytopathological Society, St. Paul, MN, USA.

Srinivas, P., 2002. Studies on genetic and pathogenic variation in R. solani, f, sp., sasakii incitant of banded leaf and sheath blight of maize. Ph.D thesis, Division of Plant Pathology. Indian Agricultural Research Institute, New Delhi.

Stodard, B.J., Harvey, P.R., Neate, S.M., Melanson, D.L., Scott, E.S., 2007. Genetic variation and pathogenicity of anastomosis group 2 isolates of Rhizoctonia solani in Australia. Mycological Research 111(8), 891-900.

Sweetingham, M.W., MacNish, G.C., 1994. Rhizoctonia isolation, Identification and Pathogenicity. A Laboratory Manual. Perth, WA, Australia, Department of Agriculture. Misc. Publ. 1492, 30.

Talbot, P.H.B., 1970. Taxonomy and nomenclature of the perfect state. In: Parmeter, J.R. (Jr.) (Ed.), Rhizoctonia solani Biology and Pathology, 20-31.

Thind, T.S., Rohit Aggarwal, 2008. Characterization and pathogenic relationships of Rhizoctonia solani isolates in a potato-rice system and their sensitivity to fungicides. Journal of Phytopathology 156(10), 615-621.

Thomas, K.S., 1925. Onderzockinger over Rhizoctonia Electr. Drukkerij “De Industries, J., Van Drutten Utrecht 98.

Toda, T., Hyakumachi, M., Arora, D.K., 1999. Genetic relatedness among and within different Rhizoctonia solani anastomosis groups as assessed by RAPD, ERIC and REP-PCR. Microbiological Research 154(3), 247258.

Vineeta, Singh., Singh, U.S., Singh, K.P., Major Singh Anil Kumar., 2002. Genetic diversity of Rhizoctonia solani isolates from rice, differentiation by morphological characteristics, pathogenicity, anastomosis behaviour and RAPD fingerprinting. Journal of Mycology and Plant Pathology 32(3), 332-344.

Williams, J.G.K., Kubelik, A.R., Livak, K.J., Kefalski, J.A., Tingey, S.V., 1990. DNA polymorphisms amplified by arbitrary primers are useful as genetic markers. Nucleic Acids Research 18(22), 6531-5. 